\title{
Optimal Inflation Threshold and Economic Growth: Ordinal Regression Model Analysis
}

\author{
Doan Van DINH ${ }^{1}$
}

Received: February 08, 2020 Revised: March 08, 2020 Accepted: April 03, 2020

\begin{abstract}
The study investigates the relationship between the inflation rate and economic growth to find out the optimal inflation threshold for economic growth. Therefore, this study applied an ordinary least square model (OLS) and the ordinal regression model, and collected the time-series data from 1996 to 2017 to test the relationship between inflation and economic growth in the short-term and long-term. The sample fits the model and is statistically significant. The study showed that $96.6 \%$ of correlation between inflation rate and economic growth are close and $4.5 \%$ of optimal inflation threshold is appropriate for economic growth. It finds that the optimal inflation threshold is base to perform economic growth, besides the inflation rate is positively related to economic growth. The results support the monetary policy appropriately. This study identifies issues for Government to consider: have a comprehensive solution among macroeconomic policies, monetary policy, fiscal policy and other policies to control and maintain the inflation and stimulate growth; have appropriate policies to regulate inflation to stimulate economic growth over the long term; set a priority goal for sustainable economic growth; not pursue economic growth by maintaining the inflation rate in the long term, but take appropriate measures to stabilize the inflation at the optimal inflation threshold.
\end{abstract}

Keywords : Economic Growth, Threshold Model, Inflation Rate.

JEL Classification Code: O11, F43, C23, C24.

\section{Introduction}

For many years the relationship between Gross Domestic Product (GDP) growth and inflation has been one of the most widely researched topics in macroeconomics. In economics, the inflation is defined as the continuous increase in the level of prices. The GDP measures the market values of a country's final consumption goods and services in a specified period. An increase in inflation means that prices have risen. The increase in inflation will lead to a decline in the purchasing power of money as well as reduction of consumption. As a result, the enterprises' commodities are surplus. Therefore, their profits are decreased and the reinvestment cannot be made. The high

${ }^{1}$ First Author and Corresponding Author. Faculty of Finance and Banking, Industrial University of Ho Chi Minh City, Vietnam [Postal Address: No. 12, Nguyen Van Bao Street, Ward 4, Go Vap District, Ho Chi Minh City, 700000, Vietnam] Email: citydinhninh@yahoo.com and doanvandinh@iuh.edu.vn

(c) Copyright: The Author(s)

This is an Open Access article distributed under the terms of the Creative Commons Attribution Non-Commercial License (http://Creativecommons.org/licenses/by-nc/4.0/) which permits unrestricted noncommercial use, distribution, and reproduction in any medium, provided the original work is properly cited. inflation can make investments less; this can also cause GDP to be decreased. It means that GDP is negatively related to the inflation. According to economist Fischer, the inflation and GDP growth was negatively related to each other. Moreover, he showed that the growth, investments and productivity were negatively related to the inflation. The capital accumulation and production growth were also negatively affected by budget deficits Mishkin (2016).

However, some exceptional cases showed that even though the high growth was not necessarily related to low inflation and small budget deficits, which emphasized the policy institutes to keep inflation at a low rate, the question is how low inflation should be. If the low inflation rate is zero or negative (deflation), does it impact on the GDP or not? The question shows that the inflation is allowable threshold that is suitable for good GDP growth, but passes over this threshold (below level or upper level), it will cause downward growth and start damaging the economy. Hence, the major literature focused on study of the suitable inflation threshold and finds out whether the relationship between the inflation and GDP growth was linear or nonlinear to set up a fit forecast model. The other authors studied China's relationship between economic growth and inflation in the 
recent years and used the method of systematic discrepancies between cross-sectional and time-series Engel curves to construct alternative estimates of Chinese growth and inflation. The estimate results indicate that the real inflation was still higher and consumption growth was overstated (Emi, Jón, \& Miao, 2016).

The author's contribution in the article is to explore the relationship between the economic growth and inflation in Vietnam from 1996 to 2017. The author applies the OLS model to find the optimal inflation threshold for the GDP growth of Vietnam - what inflation threshold is it? It means that the inflation needs to be maintained at an appropriate threshold in order to reach good economic growth. If the inflation is higher than this threshold, the growth possibility declines. Hence, the article applies OLS model that has three variables: the GDP dependent variable, inflation rate independent and inflation rate dummy variables (Dinh, 2019). To keep the GDP growth target, the Government forces on loosening or tightening fiscal and monetary policies, which will increase or decrease the inflation. These empirical studies on the inflation and economic growth showed that they had a close relationship with each other, and their relationship might be negative or positive, linear or non-linear; this depended on the inflation threshold. Moreover, the previously studied results were only exact for the specific economic context of each country.

In this paper, the author applies a linear regression model to evaluate whether the change of inflation rate impacts on GDP or not. And how does it impact? The results of the paper demonstrate that the change in Vietnam's threshold inflation rate impacts on the GDP. Why is it the case?

These contributions play an important role in planning, orienting or setting an appropriately adjusted monetary policy to promote the economic growth. The government should not make mistake deciding on monetary policy to control the inflation and economic recession. The remainder of the paper is organized as follows: Section 2 explains the data and methodology of economics; Section 3 summarizes the results; Section 4 discusses the findings and the last section gives conclusions.

The main section of an article should start with an introductory section which provides more details about the paper's purposes, motivation, research methods, and findings. The introduction should be relatively nontechnical, yet clear enough for an informed reader to understand the manuscript's contribution.

\section{Literature Review}

Most of the previous studies also applied a simple regression model and a correlation coefficient to examine empirically the relationship between the inflation and economic growth. Using the Ordinary Least Squares method, Khairul and Md. Sazib (2017) forecast an inflation threshold in Bangladesh of $8 \%$. Another study by Patrick, Prudence, and Edmond (2013), determined the relationship between the GDP growth rate and inflation rate in Ghana and applied the methods of scatter plot, correlation analysis and simple linear regression estimated by OLS; the result showed that there was a strong negative linear relationship between GDP growth rate and inflation rate in Ghana. Carolina (2015) studied the relationship between the inflation and GDP growth after the trade and financial liberalization in Brazil and applied the estimate model for the case of Brazil. The main objective of Shapan (2016) was to investigate the relationship between the inflation and economic growth in Bangladesh and applied unit root or stationary and Dickey-Fuller Test to have results, and these results indicated that Bangladesh had a statistically significant long-run positive relationship between the inflation rate and economic growth. The literature showed that each research paper applied OLS model and some other models to estimate and forecast the results of their study in each context of inflation, specific GDP growth of the country. Therefore, this article also applies the OLS model and some other tests to estimate and forecast the inflation rate and GDP growth rate of Vietnam.

Moreover, the literature limits analysis data only within the scope of a country. Thus, the author focuses on the analysis of three factors that are the inflation rate, inflation threshold and GDP, to consider whether the inflation rate impacts on GDP growth or not and how much is optimal inflation threshold. The author applies OLS model for Vietnam's data of the GDP growth and inflation rate to analyze their correlation and inflation threshold.

The other studies evaluated the relationship between the inflation rate and GDP growth of Pakistan by using the annual data of inflation and GDP growth, and using the different techniques such as OLS, FMOLS, TAR and threshold model was to estimate the real relationship between the concerned variables. These results indicated that the positive relationship between the inflation rate and economic growth rate of Pakistan was at the inflation threshold of $5.5 \%$ to $9 \%$ and confirmed the non-linear relationship between them (Gulnaz, Sidra, \& Atta, 2017).

High inflation was always correlated with increased price variability, which could lead to uncertainty about the future profitability of investment projects. Thus, the major purpose of the authors was to re-examine the existence of relationship between the inflation and economic growth of Pakistan, using the method of Ordinary Least Squares (OLS) to analyses empirically the impact of inflation on GDP growth. The results showed that the prevailing inflation was harmful to the GDP growth after a certain threshold. However, the authors' results were a negative inflation-growth relationship that was found to exist in the economy of Pakistan (Muhammad, 
Imran, \& Fatima, 2011). There are some research topics on inflation and economic growth that showed that inflation impacts on each countries' different economic growth, which belongs to each countries' monetary policy (Mustafa \& Sivarajasingham, 2019; Wulandari, Utomo, Narmaditya, \& Kamaludin, 2019; Bong \& Premaratne, 2019).

Besides, other authors had produced theoretical and empirical studies on the impact of inflation on economic growth such as Barro (2013); Faraji and Kenani (2012); Kanchan and Chandan (2011); Fakhri (2011) and Thanabalasingam (2013). Their results show that there was no consensus on the relationship between inflation and economic growth in both theoretical and empirical studies. These authors indicated that the results mostly depend on the assumptions adopted in the study. Accordingly, the theoretical literature indicated that the relationship between the inflation and economic growth could be positive, negative or neutral. Moreover, the empirical results had two models: linear or non-linear relationships (Al-Khulaifi, 2018). Keynes's research indicated that, in the short term, there would be a trade-off between the inflation and growth, i.e., a high inflation rate made GDP growth and during this period, growth and inflation rate were a positive correlation. However, in the long term, if the inflation rate increased continuously to promote GDP growth, the GDP would decrease (Mishkin, 2016).

It is known that Ordinary Least Squares model is the most common estimation method for linear models. Regression analysis is like other deductive methods. The objective of the paper is to collect a random sample from the GDP growth and inflation rate and use it to estimate their characteristic.

\section{Methodology}

According to quantity theory and inflation, the percentage change $(\% \Delta)$ of a product of two variables is approximately equal to the sum of the percentage change of the individual variables. In other words. $\% \Delta \mathrm{M}+\% \Delta \mathrm{V}=\% \Delta \mathrm{P}+\% \Delta \mathrm{Y}$ (the equation of exchange, which relates income (y or GDP) to the quantity of money $(\mathrm{M})$ and velocity $(\mathrm{V})$ : M.V = P.Y). Subtracting $\% \Delta \mathrm{Y}$ from both sides of the preceding equation, and recognizing that the inflation rate $\pi$ is equal to the growth rate of the price level $\% \Delta \mathrm{P}$, it can be written: $\pi=\% \Delta \mathrm{P}=\%$ $\Delta \mathrm{M}+\% \Delta \mathrm{V}-\% \Delta \mathrm{Y}$. Since it is assumed that the velocity is constant, its growth rate is zero, and so the quantity theory of money is also a theory of inflation (Mishkin, 2016):

$$
\pi=\% \Delta \mathbf{M}-\% \Delta \mathbf{Y} .
$$

Where:

$$
\begin{aligned}
& \% \Delta M=M_{i}-M_{i-1} / M_{i-1} \times \% ; \\
& \% \Delta Y=Y_{i}-Y_{i-1} / Y_{i-1} \times \%
\end{aligned}
$$

Formula 1 shows that there are 3 hypotheses given:

$\% \Delta \mathrm{M}>\% \Delta \mathrm{Y}, \boldsymbol{\pi}$ increases, lead to the inflation of economy, $\% \Delta \mathrm{M}=\% \Delta \mathrm{Y} . \boldsymbol{\pi}$ does not increase nor decrease (zero), the inflation of economy is zero. $\% \Delta \mathrm{M}<\% \Delta \mathrm{Y}, \boldsymbol{\pi}$ decreases under zero level, lead to the deflation of economy. This shows the inflation caused by currency, so Friedman, a Nobel laureate in economics, made a famous statement, "Inflation is always and everywhere a monetary phenomenon" and "Whenever a country's inflation rate is extremely high for a sustained period of time, its rate of money supply growth is also extremely high". However, the hypothesis on $\% \Delta M>\%$ $\Delta \mathrm{Y}$ will cause the inflation but if it is at optimum threshold, it will promote economic growth and vice versa. There were some studies for inflation threshold of 5.5\% to $9 \%$ (Gulnaz, Sidra, \& Atta, 2017) or inflation threshold of 9\% (Shahzad \& Shahnawaz, 2011) or inflation threshold of $8 \%$ (Khairul \& Md. Sazib, 2017; Dinh, 2019).

In the study, the relationship between the inflation rate and GDP growth of Vietnam is considered whether they have positive or negative and linear or non-linear relationship or not and find the optimal inflation threshold for economic growth. So, the author uses the following econometrics model for analysis.

The equation is written as follows:

$$
y_{G D P}=\beta_{1}+\beta_{2} X_{\text {Inf }}+\varepsilon
$$

The equation (2) is written as OLS model:

$$
\widehat{y_{G D P}}=\widehat{\beta_{1}}+\widehat{\beta_{2}} X_{I n f}+\varepsilon
$$

Where:

$$
\begin{aligned}
& \widehat{y_{G D P}} \text { is independent variable of GDP growth rate. } \\
& X_{I n f} \text { is dependent variable of inflation rate. } \\
& \varepsilon_{i}=y_{G D p}-\widehat{y_{G D P}}=y_{G D P}-\left(\widehat{\beta}_{1}+\widehat{\beta}_{2} X_{I n f}\right)
\end{aligned}
$$

To find out the optimal inflation threshold, the author applies two methods; firstly, the optimal inflation threshold is found by dummy method, then used the OLS method below.

$$
\widehat{y_{G D P}}=\widehat{\beta_{1}}+\widehat{\beta_{2}} X_{I n f}+\widehat{\beta}_{3} D_{I n f}+\varepsilon_{i}
$$

Where $\mathrm{K}$ is the optimal inflation threshold, is dummy variable and is defined as:

$$
D=\left\{\begin{array}{l}
1 \text { ifInf }>K \\
0 \text { ifInf } \leq K
\end{array}\right.
$$


The models are written when $\mathrm{D}$ is equal to 1 and $\mathrm{D}$ is equal to zero.

$$
\left\{\begin{array}{l}
\widehat{y_{G D P}}=\widehat{\beta}_{1}+\widehat{\beta}_{2} X_{I n f}+\widehat{\beta}_{3}(D=1)+\varepsilon_{i} \\
\widehat{y_{G D P}}=\widehat{\beta}_{1}+\widehat{\beta_{2}} X_{I n f}+\widehat{\beta}_{3}(D=0)+\varepsilon_{i}
\end{array}\right.
$$

The $\mathrm{K}$ is the inflation threshold impacting on the economic growth. Impact of inflation on the GDP growth is examined by $\beta_{2}$ coefficients, and when the inflation rate is high it is examined through $\widehat{\beta}_{2}$ coefficient plus $\widehat{\beta}_{3}$ coefficient with $\mathrm{D}=1$. If $\mathrm{D}=0$, the formula (7) is like as formula (3).

The formula (7) can be written:

$$
\widehat{y_{G D P}}=\left(\widehat{\beta_{1}}+\widehat{\beta_{3}}\right)+\widehat{\beta}_{2} X_{I n f}+\varepsilon_{i}
$$

$\widehat{\beta}_{1}, \widehat{\beta}_{2}$ are unknown constants which estimate how the sum of error squares $\left(\varepsilon_{i}\right)$ is the least.

$$
\text { i.e., } \sum_{i=1}^{22} \varepsilon_{i}^{2}=\sum_{i=1}^{22}\left(y_{i, G D P}-\left(\widehat{\beta}_{1}+\widehat{\beta}_{2} X_{i, \text { Inf }}\right)\right)^{2} \rightarrow \min
$$

As mentioned above, the major objective of the paper is to analyze and evaluate the correlation between the inflation rate and GDP growth rate as well as optimal inflation threshold. The dummy variable bases on the optimal inflation threshold. Therefore, the paper is hypothesized as follows:

: The inflation rate and GDP growth rate of Vietnam are not correlated with each other and have no optimal inflation threshold.

: The inflation rate and GDP growth rate have relationship and have the optimal inflation threshold.

The coefficient of the model is determined as follows:

Total Sum of Squares (TSS) is:

$$
\begin{aligned}
T S S & =\sum_{i=1}^{18} y_{i, i n f}^{2}=\sum_{i=1}^{18}\left(Y_{i, \text { inf }}-\overline{Y_{i n f}}\right)^{2} \\
& =\sum_{i=1}^{18} Y_{i, \text { inf }}^{2}-18\left(\overline{Y_{i n f}}\right)^{2}
\end{aligned}
$$

The Explained Sum of Squares (ESS) is the sum of squared predicted values in a standard regression model (1)

$$
\begin{aligned}
& E S S=\sum_{i=1}^{18} \hat{y}_{i, \text { inf }}^{2}=\sum_{i=1}^{18}\left(\hat{Y_{i, \text { inf }}}-\overline{Y_{\text {inf }}}\right)^{2} \text { or } \\
& E S S=\left(\hat{\beta}_{2}\right)\left(\sum_{i=1}^{18} X_{i, M S}^{2}-18\left(\bar{X}_{M S}\right)^{2}\right)
\end{aligned}
$$

The residual sum of squares (RSS), also known as the sum of squaredresiduals(SSR) or thesum of squarederrors of prediction (SSE), is the sum of the squares of residuals (deviations predicted from actual empirical values of data). It is a measure of the discrepancy between the data and an estimation model. A small RSS indicates a tight fit of the model to the data. It is used as an optimality criterion in parameter selection and model selection. The measures that indicate how well the sample regression line fits the data are denominated goodness of fit measure method. The most well-known measurement is called as coefficient of determination or the R-square $\left(R^{2}\right)$. This measure is defined in the following way:

$$
\begin{aligned}
R^{2} & =\left(\sum_{i=1}^{22} X_{i, \text { Inf }} Y_{i, G D P}\right)^{2} / \sum_{i=1}^{22} x_{i, \text { Inf }}^{2} \sum_{i=1}^{18} y_{i, G D P}^{2} \\
& =1-R S S / T S S
\end{aligned}
$$

Therefore, $\left(R^{2}\right)$ is the proportion of the total sum of squares (TSS) which is explained by the regression (ESS): that is to say which is explained by the model. It is said that 100 is the percentage of the sample variation in y explained by $x$. So, it is equal to 1 minus the proportion of the total sum of squares (Dinh, 2018).

According to the definition of $\left(R^{2}\right)$, the following must be accomplished $0 \leq R^{2} \leq 1$

Correlation coefficient ( $r$ ) is a statistical indicator that measures correlations between two variables, such as the GDP growth rate $\left(Y_{G D P}\right)$ and the inflation rate (Inf) $\left(X_{\text {inf }}\right)$. The correlation coefficient is from -1 to 1 . The correlation coefficient equals to 0 (or approximately equal to 0 ) i.e. the two variables are not related to each other; Conversely, if the coefficient is -1 or 1 , the two variables have an absolute relationship. If the value of the correlation coefficient is negative $(r<0)$ i.e. when $\mathrm{x}$ increases, $\mathrm{y}$ decreases (and vice versa, when $\mathrm{x}$ decreases $y$ increases); If the correlation coefficient is positive ( $r>0)$, it means that when $\mathrm{x}$ increases, then $\mathrm{y}$ also increases and $\mathrm{y}$ decreases, $x$ also decreases Dinh (2019).

T-Test method is applied to test hypothesis $\mathrm{H}$ that can be based on the results of T-test, it is tested on left side, on right side or on both sides of the standard distribution function. In case of both sides 1: H0: if $\beta_{2}=\beta_{2}^{*}$ and $\mathrm{H} 1$ : if $\beta_{2} \neq \beta_{2}^{*}, \mathrm{H} 0$ is rejected with condition of $|t|>t_{\alpha / 2, d f}$. In case of left side: $\mathrm{H} 0$ : if $\beta_{2} \geq \beta_{2}^{*}$ and : if $\beta_{2}<\beta_{2}^{*}, \mathrm{H} 1$ is rejected with condition of $|t|<-t_{\alpha / 2, d f}$. In case of right side: H0: if $\beta_{2} \leq \beta_{2}^{*}$ and H1 : if $\beta_{2}>\beta_{2}^{*}$, rejected with condition of $|t|>t_{\alpha / 2, d f}$. Where: $\beta_{2}^{*}$ is the hypothetical value of $\beta_{2}|t|$ is the absolute value of $\mathrm{t}, t_{\alpha}$ or $t_{\alpha / 2}$ is the critical value of $\mathrm{t}$ at the significant level $\alpha$ or $\alpha / 2$ and df is degrees of freedom with $(\mathrm{n}-2)$ for a two-variable model and with $(\mathrm{n}-3)$ for a three-variable model, etc. The $\beta_{1}$ is tested like $\beta_{2}$. Otherwise, all of these cases show that the research fits as expected that there is a relationship between inflation rate and GDP growth rate and also there is an optimal inflation thresholdDinh (2020). 
The percentage of annual GDP growth at market prices is based on constant local currency. GDP is the sum of gross value added by all resident producers in the economy plus any product taxes and minus any subsidies not included in the value of the products.

The inflation is measured by the consumer price index and reflects the annual percentage change in the cost to the average consumer of acquiring a basket of goods and services. The dataset is collected from the World Development Index (WDI) that is the main dataset on development indicators of the World Bank and compiled from official international sources. It presents available and accurate data on current global development. The dataset is to analyze and forecast relationship between the inflation rate and GDP growth rate, in case of inflation, what should the government do? The results below show the control of the government's monetary policy to grow the GDP.

The article applies the threshold regression model to find the optimal inflation threshold by the dummy variable method in two cases: the first case: the inflation threshold is less than or equal to $5 \%$ or the threshold is greater than $5 \%$. The second case: the inflation threshold is smaller or equal to
$4.5 \%$ or greater than $4,5 \%$. These cases are compared with each other to find the optimal inflation threshold and statistical significance. When there is an optimal inflation threshold result, the model is forecasted on the inflation impact on the DGP. The results are described in the section below.

\section{Results}

The results in this section are presented by the estimation model following methodology and dataset in the previous section. The bivariate analysis model is done to consider the relationship between the GDP growth and inflation rate rigorously and determine the true relationship between these two variables as well as find the optimal inflation threshold for GDP growth of Vietnam. The first case, the Parameter Estimates is computed by threshold regression model at $\mathrm{K}$ $\leq 5 \%$ or $\mathrm{K}>5 \%$ when it is run by the dummy variables. The second case, the Parameter Estimates is computed by threshold regression model at $\mathrm{K} \leq 4.5 . \%$ or $\mathrm{K}>4.5 \%$ when it is run by the dummy variables. The Parameter estimates table is the core of the output and shows the relationship between our explanatory variables and the outcome (see Table 1).

Table 1: The Parameter estimates of GDP growth and Dummy Inflation in Vietnam

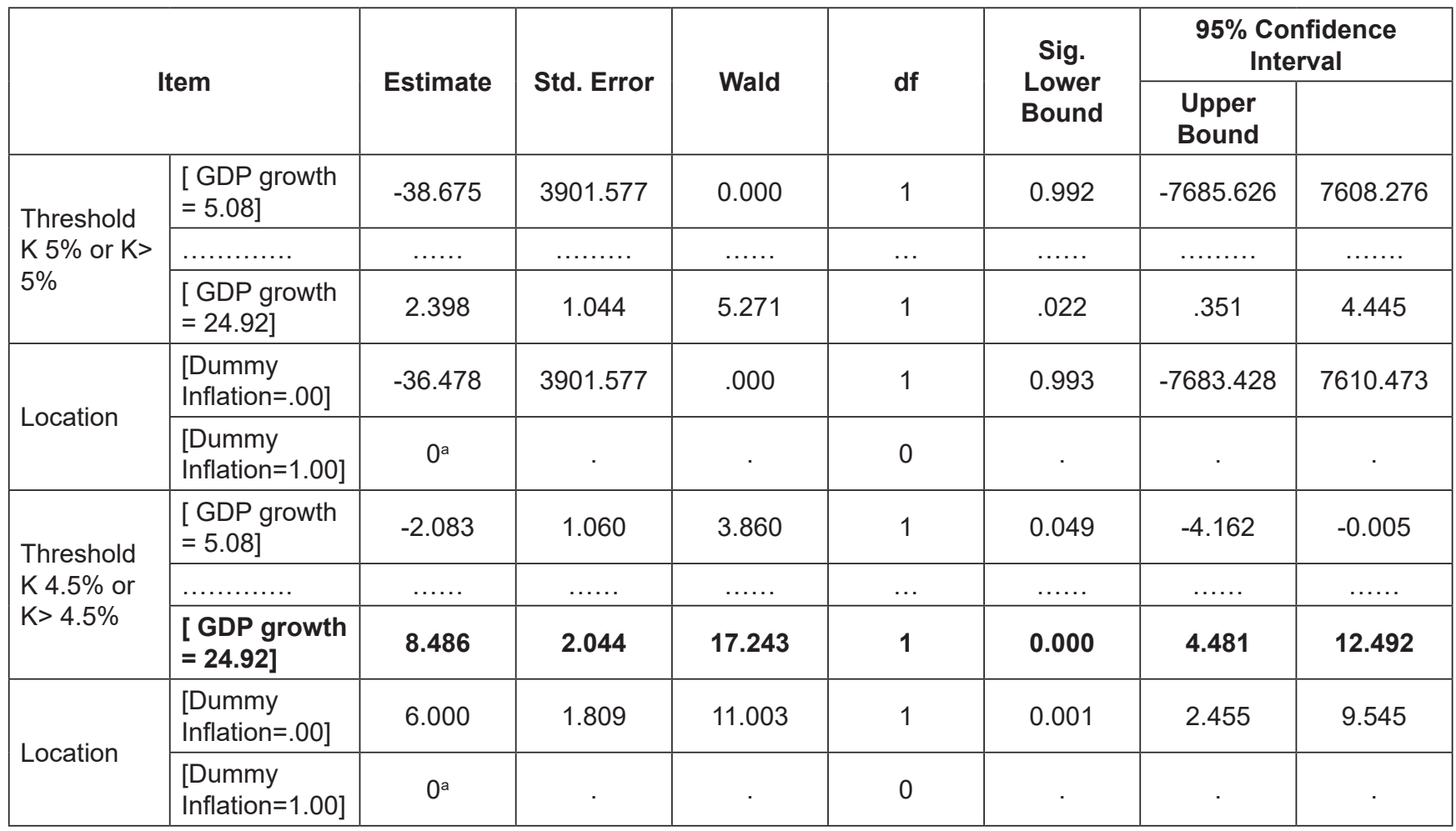

$N=22$

Link function: Logit.

a. This parameter is set to zero because it is redundant. 
Table 2: Model Fitting Information

\begin{tabular}{|l|c|c|c|c|}
\hline \multicolumn{1}{|c|}{ Model } & $\mathbf{- 2}$ Log Likelihood & Chi-Square & df & Sig. \\
\hline Intercept Only & 65.298 & & & \\
\hline Final & 40.975 & 24.323 & 1 & 0.000 \\
\hline Link function: Logit. & & & & \\
\hline
\end{tabular}

Table 3: Goodness-of-fit and Pseudo R-Square

\begin{tabular}{|l|c|c|c|}
\hline & Chi-Square & df & Sig. \\
\hline Pearson & 5.660 & 20 & 0.999 \\
\hline Deviance & 5.444 & 20 & 0.999 \\
\hline Link function: Logit. \\
\hline
\end{tabular}

\begin{tabular}{|l|l|}
\hline Cox and Snell & 0.669 \\
\hline Nagelkerke & 0.670 \\
\hline McFadden & 0.179 \\
\hline Link function: Logit. \\
\hline
\end{tabular}

Table 4: Test of Parallel Lines ${ }^{a}$

\begin{tabular}{|c|c|c|c|c|}
\hline Model & -2 Log Likelihood & Chi-Square & df & Sig. \\
\hline Null Hypothesis & 40.975 & & & \\
\hline General & $32.767^{b}$ & $8.207^{c}$ & 20 & 0.990 \\
\hline \multicolumn{5}{|c|}{$\begin{array}{l}\text { The null hypothesis states that the location parameters (slope coefficients) are the same across response categories. } \\
\text { a. Link function: Logit. } \\
\text { b. The log-likelihood value cannot be further increased after maximum number of step-halving. } \\
\text { c. The Chi-Square statistic is computed based on the log-likelihood value of the last iteration of the general model. Validity of the test is } \\
\text { uncertain. }\end{array}$} \\
\hline
\end{tabular}

The model fitting information is determined before the model starts looking at the effects of each explanatory variable in the model; it needs to determine whether the model improves our ability to predict the outcome. It is to see whether it has significantly improved the fit to the data. The Model fitting Information table gives the 2-log likelihood (see Table 2).

The next table in the output is the Goodness-of-Fit table. This table contains Pearson's chi-square statistic for the model. The Goodness-of-Fit table is intended to test whether the observed data are consistent with the fitted model (see Table 3).
In linear regression model, R-square (the coefficient of determination) summarizes the proportion of variance in the outcome that can be accounted for by the explanatory variables, with larger R-square values indicating that more of the variation in the outcome can be explained up to a maximum of 1 . For logistic and ordinal regression models, they are not possible to compute R-square statistic the same as in linear regression model so three approximations are computed instead. The results of ordinal regression models' the R-square are compared with the results of linear

Table 5: Vietnam's Correlations of GDP growth and Inflation rate

\begin{tabular}{|l|l|c|c|c|}
\hline \multicolumn{2}{|c|}{ Model } & GDP growth & Inflation & Dummy Inflation \\
\hline \multirow{4}{*}{ Pearson Correlation } & GDP growth & 1.000 & 0.982 & -.663 \\
\cline { 2 - 5 } & Inflation & 0.982 & 1.000 & -.654 \\
\cline { 2 - 5 } & Dummy Inflation & -0.663 & -0.654 & 1.000 \\
\hline \multirow{4}{*}{ Sig. (1-tailed) } & GDP growth & $\cdot$ & 0.000 & 0.000 \\
\cline { 2 - 5 } & Inflation & 0.000 &. & 0.000 \\
\cline { 2 - 5 } & Dummy Inflation & 0.000 & 0.000 &. \\
\hline \multirow{3}{*}{$\mathrm{N}$} & GDP growth & 22 & 22 & 22 \\
\cline { 2 - 5 } & Inflation & 22 & 22 & 22 \\
\cline { 2 - 5 } & Dummy Inflation & 22 & 22 & 22 \\
\hline
\end{tabular}


regression models' the R-square in the next section to see the difference between them (see Table 4).

The model can be evaluated by the appropriateness of this assumption through the "test of parallel lines". This test compares the ordinal model which has one set of coefficients for all thresholds (labelled Null hypothesis - Table 5), to a model with a separate set of coefficients for each threshold (labelled General).

From the threshold result, it shows the optimal inflation rate of $4.5 \%$. This result is the basis for applying a linear model to predict the impact of inflation on economic growth as follows:

It is known that the purpose of the Pearson correlation test is to determine the close linear correlation between the dependent variables and the independent variables since the condition for the regression is the first correlation evaluation (see Table 5).

Besides, the results in Table 6 showed that the value of R-square is in the range from 0 to 1 . If the square of $\mathrm{R}$ is close to 1, the dependent variable and the independent variable are strongly correlated. In other words, the inflation variable impacts greater on the GDP variable and vice versa.

Table 6: Model Summary

\begin{tabular}{|l|c|c|c|c|}
\hline Model & $\mathbf{R}$ & $\begin{array}{c}\mathbf{R} \\
\text { Square }\end{array}$ & $\begin{array}{c}\text { Adjusted } \\
\text { R Square }\end{array}$ & $\begin{array}{c}\text { Std. Error of } \\
\text { the Estimate }\end{array}$ \\
\hline 1 & $0.983^{\text {a }}$ & 0.966 & 0.962 & 1.06532 \\
\hline \multicolumn{5}{|c|}{ Predictors: (Constant), Dummy Inflation, Inflation } \\
b. Dependent Variable: GDP growth \\
\hline
\end{tabular}

Otherwise, the analysis of variance (ANOVA) is a statistical method for analyzing the total variability of the dependent variables into multiple parts and each part is attributed to the variation of an individual interpretation variable or a group of explanatory variables. This method is used to test hypothesis zero (Ho) to determine whether the samples are statistically significant (see Table 7).

In addition, the coefficient table is to determine the Beta normalized regression coefficients column, value column Sig, and VIF column. These results show whether the data conditions are fit for the model (see Table 8).

Firstly, for the sig value tests for each independent variable, the sig is less than or equal to 0.05 , meaning that the variable is significant in the model, whereas the sig is greater than 0.05 , it means that the independent variable needs to be removed.

Secondly, for Beta standardized regression coefficients, in all regression coefficients, the independent variables have the largest Beta, most variables affect the change of the dependent variables. Therefore, when proposing solutions, the forecast model is focused more on factors that have large Beta. Besides, the Beta unstandardized regression coefficient indicates that each change of the independent variables makes the change of the dependent variables, given that all of the other variables in the model are held constant.

Finally, for VIF, this value is used to check for multicollinearity phenomenon. According to the theory of many written documents, VIF $<2$ will not have multicollinearity and vice versa.

Table 7; ANOVA ${ }^{\mathrm{a}}$ of GDP growth and Inflation rate in Vietnam

\begin{tabular}{|l|l|l|l|l|l|l|}
\hline \multicolumn{2}{|c|}{ Model } & \multicolumn{1}{c|}{ Sum of Squares } & df & \multicolumn{1}{c|}{ Mean Square } & F & Sig. \\
\hline \multirow{4}{*}{1} & Regression & 608.746 & 2 & 304.373 & 268.194 & $0.000^{\mathrm{b}}$ \\
\cline { 2 - 7 } & Residual & 21.563 & 19 & 1.135 & & \\
\cline { 2 - 7 } & Total & 630.309 & 21 & & & \\
\hline \multicolumn{2}{|l|}{$\begin{array}{l}\text { a. Dependent Variable: GDP growth } \\
\text { b. Predictors: (Constant), Dummy Inflation, Inflation }\end{array}$}
\end{tabular}

Table 8: Coefficients ${ }^{a}$ of GDP growth and Inflation rate in Vietnam

\begin{tabular}{|c|c|c|c|c|c|c|c|c|c|}
\hline \multirow[t]{2}{*}{ Model } & \multicolumn{2}{|c|}{$\begin{array}{l}\text { Unstandardized } \\
\text { Coefficients }\end{array}$} & \multirow{2}{*}{$\begin{array}{c}\begin{array}{c}\text { Standardized } \\
\text { Coefficients }\end{array} \\
\text { Beta }\end{array}$} & \multirow[t]{2}{*}{$\mathbf{t}$} & \multirow[t]{2}{*}{ Sig. } & \multicolumn{2}{|c|}{$\begin{array}{l}95.0 \% \text { Confidence } \\
\text { Interval for B }\end{array}$} & \multicolumn{2}{|c|}{ Collinearity Statistics } \\
\hline & B & $\begin{array}{c}\text { Std. } \\
\text { Error }\end{array}$ & & & & $\begin{array}{l}\text { Lower } \\
\text { Bound }\end{array}$ & $\begin{array}{l}\text { Upper } \\
\text { Bound }\end{array}$ & Tolerance & VIF \\
\hline (Constant) & 7.045 & 0.599 & & 11.764 & 0.000 & 5.792 & 8.299 & & \\
\hline Inflation & 0.944 & 0.055 & 0.959 & 17.106 & 0.000 & .828 & 1.059 & 0.573 & 1.746 \\
\hline $\begin{array}{l}\text { Dummy } \\
\text { Inflation }\end{array}$ & -0.385 & 0.610 & -0.035 & -0.631 & 0.535 & -1.663 & 0.892 & 0.573 & 1.746 \\
\hline
\end{tabular}




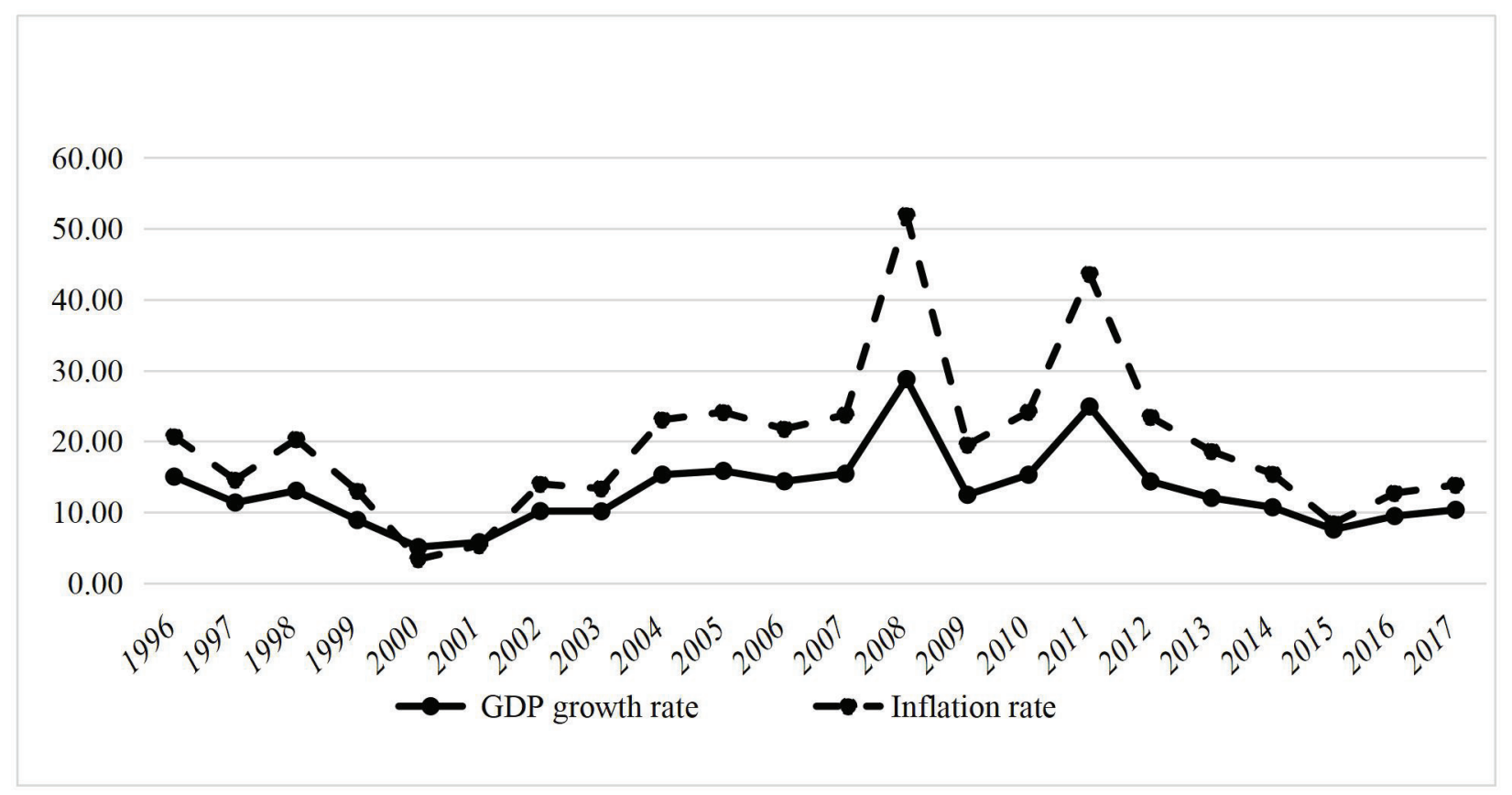

Figure 1: Vietnam's GDP growth rate and Inflation rate

Figure 1 shows the fluctuation between the inflation rate and GDP growth rate. The results showed that the inflation rate was negative in 2000, 2001 (deflation). This made the GDP growth rate also fallen. In the period of 2008 and 2011, the results also showed that the money supply increased faster than the economic growth, leading to the high inflation. In 2015 , the inflation rate decreased approximately to zero, then the inflation rate continued to increase in the next years.

The results of statistical analysis are the basis for setting a forecast model for the inflation rate and GDP growth rate.

$(\mathrm{GDP})=12.102+7.045 \operatorname{Inf}+(-.385) \mathrm{D}$,

In case $\mathrm{D}=1$, the model is written:

$(\mathrm{GDP})=(12.102+(-.385))+7.045 \mathrm{Inf}$,

In case $\mathrm{D}=0$, the model is written:

$(\mathrm{GDP})=12.102+7.045 \mathrm{Inf}$

The analysis results are the basis to assess how does the inflation rate impact on GDP growth rate? And how does government control the inflation rate to stabilize the economy? These issues are discussed in the next section.

\section{Discussion}

The threshold of the ordinal regression model is applied to find the optimal inflation threshold. This result is the basis for establishing a dummy linear forecast model. The research results show that the optimal inflation threshold and forecast model are suitable for the Vietnamese economy so that scholars and macro managers can refer to the experimental results and highly reliable data. Discussion is based on the problems on the fit of data with the model, the optimal inflation threshold and evaluation of inflation impact on economic growth through the forecast model.

The first problem of the optimal inflation threshold: the model selects two levels of inflation, which is $\mathrm{k}=5 \%$ and $\mathrm{k}=4.5 \%$, the parameter estimate table shows threshold ( $\mathrm{K} \leq 5 \%$ or $\mathrm{K}>5 \%$ ). This represents the response variable in the ordered logistic regression. The threshold estimates for [ GDP growth $=5.08$ ] is the cut off value between low and middle "GDP growth" and the threshold estimates for [ GDP growth $=24.92$ ] that represents the cut-off value between middle and high GDP growth. For the threshold $(\mathrm{K} \leq 4.5 \%$ or $\mathrm{K}>4.5 \%)$, it is similarly explained as the threshold $(\mathrm{K} \leq 5 \%$ or $\mathrm{K}>5 \%)$. Moreover, the Parameter Estimates table (Threshold $\mathrm{K} \leq 5 \%$ or $\mathrm{K}>5 \%$ ) shows the coefficients, their standard errors, the Wald test and associated p-values (Sig.), and the 95\% confidence interval of the coefficients. Both "GDP growth" and "Dummy Inflation" are not statistically significant, leading to reject the model. So, this model is not fit. Therefore, the inflation threshold model $(\mathrm{K} \leq 4.5 \%$ or $\mathrm{K}>4.5 \%)$ is tested and then the result shows p-values (Sig) of "GDP growth" and "Dummy Inflation" variables are not statistically significant $\mathrm{p}<0.05$ (see Table 1 ). It can say that for oneunit increase in inflation (i.e., going from 0 to $4,5 \%$ ), GDP growth rate is expected to increase by $6 \%$ in the estimate column of Table 1 , given that all of the other variables in 
the model are held constant. The inflation threshold of $4,5 \%$ is also the optimal inflation threshold that is found out and it is applied to set up the forecast model of inflation impact on the GDP growth rate.

The result shows that the model with inflation thresholds of $\mathrm{K} \leq 4.5 \%$ or $\mathrm{K}>4.5 \%$ is fit to the research model. Table 2 of the Model fitting information that has the significant chisquare statistic $(p<.0005)$ indicates that the final model gives a significant improvement over the baseline intercept-only model. It means that the model gives better predictions than if the result is guessed based on the marginal probabilities for the outcome categories. Therefore, this model has a sig. of $0.000(p<0.005$, accepted H1); this indicates that the dataset fits with the model. Otherwise, the Goodness-of-Fit table shows that from the null hypothesis that fit is good. If this hypothesis is not rejected (i.e., if the p-value is large), then the model is concluded that the data and the model predictions are similar and the model is good. However, the null hypothesis is rejected, if $\mathrm{p}<0.05$, then the model does not fit the data well (rejected H0, accepted H1). Thereof, the analysis of the results suggests that the model fit very well ( $p$ $=0.999$ i.e. $\mathrm{p}>0.05$ ).

Besides, what constitutes a "good" R-square value depends upon the nature of the outcome and the explanatory variables. Here, the Pseudo R-square Statistics is $67 \%$ (i.e. Nagelkerke $=67 \%$ ) and R-square value of the linear regression model is $97 \%$. This is also the difference between the ordinal regression model and linear regression model. The R-square value indicates that it is explained a relatively large proportion of the variation between the inflation rate with GDP growth rate i.e. variable of inflation rate and variable of GDP growth rate have a close correlation and they are positive at the inflation threshold $\mathrm{K} \leq 4.5 \%$ and negative at inflation threshold $\mathrm{K}>4.5 \%$. In other words, the Inflation rate greatly impacts on the GDP growth rate. The results in Table 5 indicate that if the general model gives a significantly better fit to the data than the ordinal (proportional odds) model (i.e. if $\mathrm{p}<0.05$ ) then it is led to reject the assumption of proportional odds. However, the result in Table 5, given the significant value is higher than $\mathrm{p}$-value ( $\mathrm{p}=0.990, \mathrm{p}>0.05$, accepted H1). So, the model is fit and accepted to a research result.

The third problem is the impact of inflation on economic growth: In order to assess the suitability of the data for the model, the result also indicates the R-square of the sum of $0.966 \%$ and the coefficient column, the value of the Sig column and the VIF column in table ANOVA show Sig: $p$ $=000$ leading to $\mathrm{P}<0.05$, it is statistically significant, VIP 1,746 , VIP $<2$, they are not collinearity statistics (accepted H1). However, the results in the coefficient table show that the dummy inflation variable is not statistically significant because $\mathrm{p}=0.535, \mathrm{p}>0.05$ (accepted H1). In this case, if $\mathrm{D}=$ 1 , i.e. $K>4.5 \%$, then this dummy variable is not statistically significant when it is explained to the dependent variable, if $\mathrm{D}=0$, then the model only has two variables that is inflation variable and economic growth variable.

The linear regression model by the OLS method is implemented with some assumptions and the model is only meaningful when these assumptions are appropriate.

Therefore, to ensure the reliability of the model, the detection of violation of assumptions is necessary. The model is tested by the assumption of a normal distribution of residuals and a linear relationship (see Figure 1). The results show that standardized residuals are distributed according to the shape of the normal distribution. There is a bell curve on the histogram that is the normal distribution line; we see the histogram curve corresponding to that bell curve. Moreover, the mean value is $3.47 \mathrm{E}-18$ which is approximately 0 , and the standard deviation is 0.951 which is approximately 1 , confirming the normalized residuals to follow the normal distribution (accepted H1). The Normal P-P Plot of Regression Standardized Residual verifies that the observed values and expected values are all near the diagonal, and it indicates that the regression standardized residuals have a normal distribution. Testing by Normal P-P Plot shows the values of the percentile of the distribution of the variable according to the percentile of the normal distribution. Observing the level of actual points and focusing closely on the expected straight-line show that the research dataset is good, standardized remainder is distributed closely to normal distribution.

The results (see Table 8 ) also show that the correlation coefficient is $\beta^{\wedge}$ (slope) such as: $\left(\beta \_2\right)=0.944,\left(\beta \_3\right)=-$ 0.385 and the intersection at the vertical axis is $\left(\beta \_1\right)=7.045$. The linear regression equation is written: $\mathrm{Y} G \mathrm{GP}=7.045+$ $0.944 \mathrm{Inf}+(0.385) \mathrm{D}$. Because this dummy variable is not statistically significant when it is explained to the dependent variable. However, if $\mathrm{D}=1,\left(\beta \_1\right)=7.045+(0.355)=6.69$, i.e. GDP is reduced. So, the model is written: GDP $=7.045+$ 0.944 Inf. Meaning that the inflation of the economy increases by $1 \%$ in optimal inflation threshold $(\mathrm{K} \leq 4.5 \%)$, the GDP growth rate increases by $7.989 \%$. This result suggests that the change in the inflation equates to the change in the GDP growth rate. From this forecast equation, the economy can forecast change in the GDP growth rate in the future when the inflation increases by $1 \%$.

\section{Conclusions}

The relationship between the inflation and economic growth is a topic, which had been discussed by many authors for different countries referred above. Some studies suggested a low inflation rate to stimulate the economic growth while a few studies suggested the high inflation rate to grow the economy fast. This is only fit for the economy of each country in a specific research context. 
The research results and the discussions above show the importance of inflation and economic growth. Why is it the case? Any country is concerned about inflation index for economic growth and sustainability. Because, if the inflation rate exceeds the optimal inflation threshold, it will cause the decreased GDP growth. Therefore, scholars and macro managers should consider the following issues:

Firstly, the inflation and economic growth exist in the short-term and long-term relationship, so the Government needs to have a comprehensive solution among macroeconomic policies, monetary policy, fiscal policy and other policies to control and maintain the inflation and stimulate growth. For the Vietnam economy, the optimal inflation threshold is $4.5 \%$.

Secondly, in the short term, it is necessary to set up measures to promote economic growth and control inflation at an appropriate level. However, the research results show that there is a positive relationship between inflation and short-term economic growth that does not cause inflation. This is also consistent with the research results of Irving Fisher. However, in the long term, the Government needs to have appropriate policies to regulate inflation to stimulate economic growth.

Thirdly, the Government should set a priority goal for sustainable economic growth. For economic management policy, the Government needs to set specific goals to ensure that economic growth and inflation control are at the optimal inflation threshold. In addition, the Government should not expect high growth rate by loosening monetary policy, which will cause high inflation.

Fourthly, the research shows that between growth and inflation, there is a positive relationship in the short term. However, in the long-term the inflation rate increases faster than the economic growth rate and has a negative relationship with the rate of economic growth (see Figure 3 ). Therefore, the Government should not pursue economic growth by maintaining the inflation rate in the long term, but it needs to take appropriate measures to stabilize the inflation at the optimal inflation threshold to promote the sustainable economic growth and avoid money supply shocks.

\section{References}

Al-Khulaifi, A. S. (2018). An Empirical Study on Inflation and Economic Growth in Qatar. International Journal of Economics and Financial Research, 4(9), 292-296. Retrieved from https:// arpgweb.com/pdf-files/ijefr4(9)292-296.pdf

Barro, R. (2013). Inflation and Economic Growth. Annals Of Economics And Finance, 14(1), 121-144. Retrieved from http:// down.aefweb.net/AefArticles/aef140106Barro.pdf

Bong, A., \& Premaratne, G. (2019). The Impact of Financial Integration on Economic Growth in Southeast Asia. Journal of Asian Finance, Economics and Business, 6(1), 107-119. doi:10.13106/jafeb.2019.vol6.no1.107
Carolina, T. (2015). Inflation and economic growth in an open developing country: the case of Brazil. Cambridge Journal of Economics, 3(9), 1263-1280.

Dinh, D. V. (2018). World Crude Oil Prices Impact On Consumer Price Index. Advances and Applications in Statistics, 52(1), 3354. doi:10.17654/AS052010033

Dinh, D. V. (2019). Analysed Money Supply And Inflation: Evidence From Vietnam Economy. Advances and Applications in Statistics, 56(2), 125-142. doi:10.17654/AS056020125

Dinh, D. V. (2019). Applied Individual Investment Risk Measurement Method to Forecast Expected Return Rate. International Journal of Applied Mathematics and Statistics ${ }^{\mathrm{TM}}$, 58(3), 60-72. Retrieved from http://www.ceser.in/ceserp/index. php/ijamas/article/view/6177

Dinh, D. V. (2019). Money supply and inflation impact on economic growth. Journal of Financial Economic Policy, 11(3), 457-473. doi:10.1108/JFEP-10-2018-0152

Dinh, D. V. (2020). Forecasting domestic credit growth based on ARIMA model: Evidence from Vietnam and China. Management Science Letters, 10(5), 1001-1010. doi:10.5267/j. msl.2019.11.010

Gulnaz, H., Sidra, N., \& Atta, M. (2017). Threshold Modeling for Inflation and GDP Growth. MPRA Paper, 90130(25), 1-24. Retrieved from https:/mpra.ub.uni-muenchen.de/79649/

Kanchan, D., \& Chandan, K. M. (2011). Relationship between Inflation and Economic Growth in Malaysia An Econometric Review. Proceedings of International Conference on Economics and Finance Research, 4(1), 415-419. Retrieved from http:// www.ipedr.com/vol4/82-F10100.pdf

Emi, N., Jón, S., \& Miao, L. (2016). Are Chinese Growth and Inflation Too Smooth? Evidence from Engel Curves. American Economic Journal: Macroeconomics, 8(3), 113-144. doi:10.3386/w19893

Fakhri, H. (2011). Relationship between in ation and economic growth in Azerbaijani economy: is there any threshold effect? MPRA Paper, 33494(23), 1-9. Retrieved from https://mpra. ub.uni-muenchen.de/33494/3/MPRA_paper_33494.pdf

Faraji, k., \& Kenani, M. (2012). Impact Of Inflation On Economic Growth: A Case Study Of Tanzania. Asian Journal of Empirical Research, 3(4), 363-380. Retrieved from http://www.aessweb. com/pdf-files/1-3(4)2013-AJER-363-380.pdf

Khairul, K. S., \& Md. Sazib, M. (2017). Inflation and Economic Growth: An Empirical Evidence of Bangladesh (1986-2016). International Journal of Economics and Financial Issues, 7(5), 454-464. Retrieved from https://www.econjournals.com/index. php/ijefi/article/view/5385

Mishkin, F. (2016). The Economics of Money, Banking and Financial Markets. New York, NY: Columbia University.

Muhammad, A., Imran, S. C., \& Fatima, F. (2011). Does Inflation Affect Economic Growth? The case of Pakistan. Pakistan Journal of Social Sciences (PJSS), 31(1), 51-64. Retrieved from https://pdfs.semanticscholar. org/7dbf/f519005112cb731d7ccaaef0407ea5702e 28 . 
pdf?_ga=2.31479163.451644530.15727702361913168746.1572770236

Mustafa, A. M., \& Sivarajasingham, S. (2019). Dynamic Linkages between Food Inflation and Its Volatility: Evidence from Sri Lankan Economy. Journal of Asian Finance, Economics and Business, 6(4), 139-145. doi:10.13106/jafeb.2019.vol6.no4.139

Patrick, E., Prudence, A. O., \& Edmond, H. (2013). The Relationship Between Gdp Growth Rate And Inflationary Rate In Ghana: An Elementary Statistical Approach. Academic Research International, 4(5), 310-318. Retrieved from http://www.savap. org.pk/journals/ARInt./Vol.4(5)/2013(4.5-31).pdf

Shahzad, H., \& Shahnawaz, M. (2011). Inflation and Economic Growth: Evidence from Pakistan. International Journal of Economics and Finance, 5(3), 262-276. doi:10.5539/ijef. $\mathrm{v} 3 \mathrm{n} 5 \mathrm{p} 262$
Shapan, C. M. (2016). Inflation and Its Impacts on Economic Growth of Bangladesh. American Journal of Marketing Research, 2(1), 17-26. Retrieved from http://www.aiscience. org/journal/paperInfo/ajmr?paperId=2477

Thanabalasingam, V. (2013). Inflation and Economic Growth: A Dynamic Panel Threshold Analysis for Asian Economies. GRIPS Discussion Paper, 23(4), 12-17. doi:10.1016/j. asieco.2013.04.001

Wulandari, D., Utomo, S. H., Narmaditya, B. S., \& Kamaludin, M. (2019). Nexus between Inflation and Unemployment: Evidence from Indonesia. Journal of Asian Finance, Economics and Business, 6(2), 269-275. doi:10.13106/jafeb.2019.vol6.no2.269 
